\title{
A Novel Design of Morlet Wavelet to Solve the Dynamics of Nervous Stomach Nonlinear Model
}

\author{
Zulqurnain Sabir $^{1} \cdot$ Muhammad Asif Zahoor Raja $^{2}$ - S. R. Mahmoud ${ }^{3} \cdot$ Mohammed Balubaid $^{4} \cdot$ Ali Algarni $^{5}$. \\ Abdulaziz H. Alghtani ${ }^{6}$. Ayman A. Aly ${ }^{6}$ Dac-Nhuong Le ${ }^{7,8}$
}

Received: 6 April 2021 / Accepted: 10 December 2021

(c) The Author(s) 2021

\begin{abstract}
The present study introduces a novel design of Morlet wavelet neural network (MWNN) models to solve a class of a nonlinear nervous stomach system represented with governing ODEs systems via three categories, tension, food and medicine, i.e., TFM model. The comprehensive detail of each category is designated together with the sleep factor, food rate, tension rate, medicine factor and death rate are also provided. The computational structure of MWNNs along with the global search ability of genetic algorithm (GA) and local search competence of active-set algorithms (ASAs), i.e., MWNN-GA-ASAs is applied to solve the TFM model. The optimization of an error function, for nonlinear TFM model and its related boundary conditions, is performed using the hybrid heuristics of GA-ASAs. The performance of the obtained outcomes through MWNN-GA-ASAs for solving the nonlinear TFM model is compared with the results of state of the article numerical computing paradigm via Adams methods to validate the precision of the MWNN-GA-ASAs. Moreover, statistical assessments studies for 50 independent trials with 10 neuron-based networks further authenticate the efficacy, reliability and consistent convergence of the proposed MWNN-GA-ASAs.
\end{abstract}

Keywords TFM nonlinear system $\cdot$ Morlet function $\cdot$ Neural networks $\cdot$ Adams method $\cdot$ Active set $\cdot$ Statistical soundings

Dac-Nhuong Le

ledacnhuong@duytan.edu.vn

Zulqurnain Sabir

zulqurnain_maths@hu.edu.pk

Muhammad Asif Zahoor Raja

rajamaz@yuntect.edu.tw

S. R. Mahmoud

samsam73@yahoo.com

Mohammed Balubaid

mbalubaid@kau.edu.sa

Ali Algarni

ahalgarni@kau.edu.sa

Abdulaziz H. Alghtani

a.ghtani@tu.edu.sa

Ayman A. Aly

aymanaly@tu.edu.sa

1 Department of Mathematics and Statistics, Hazara

University, Mansehra, Pakistan
2 Future Technology Research Center, National Yunlin University of Science and Technology, 123 University Road, Section 3, Douliou, Yunlin 64002, Taiwan, ROC

3 GRC Department, Faculty of Applied Studies, King Abdulaziz University, Jeddah, Saudi Arabia

4 Department of Industrial Engineering, Faculty of Engineering, King Abdulaziz University, Jeddah, Saudi Arabia

5 Statistics Department, Faculty of Science, King Abdulaziz University, Jeddah, Saudi Arabia

6 Department of Mechanical Engineering, College of Engineering, Taif University, PO Box 11099, Taif 21944, Saudi Arabia

7 Institute of Research and Development, Duy Tan University, Da Nang 550000, Vietnam

8 School of Computer Science, Duy Tan University, Da Nang 550000, Vietnam 


\section{Introduction}

Solutions of bioinformatics models with deterministic and stochastic numerical technique have paramount importance for the research community due to their exhaustive applications in broad displaces of science and technology. A bioinformatics model for stomach dynamics system with representation of three classes, i.e., tension, food and medicine, i.e., TFM-based ODEs model is taken as a system model for the presented study.

\subsection{Overview of Nonlinear Stomach Model}

In the human body, every organ has its own significance and get disturb with the loss/weakness of any organ. The structure of the human body is linked with one another, e.g., ear is associated with the nose, the nose is connected to the eye, etc. In human structure, the role of the stomach is significant due to the connections of numerous organs in maintaining the health of humans [1]. The stomach's role in the human's body is very crucial and the ancient Greeks observed the intimidating gastric ingredients related with stomach. At the start of sixteenth century, Helmont and Paracelsus [2, 3] were aware that stomach comprises acid in the digestion process. The solvent properties of gastric juice of the animal materials accessible by Spallanzani and Reaumur [4, 5]. William [6] investigated the emission nature of digestive acid and Beaumont [7] analyzed the patient of a gastric fistula. In the nineteenth century, the innovation of the gastric secretion is organized by the vagotomy ablation and celiac axis as curing interventions. Dale and Laidlaw [8] investigated the histamine using the complex gastric emission, which is focused by the Popielski investigations using the histamine properties of digestive radiation [9]. These stated discoveries helped us to identify the digestive disease using the affected progresses in the pharmacological connotation of peptic ulcer with H2-receptor discoveries of Sir James Black two centuries ago [10]. Edkins [11] presented the gastrin performance and Bayliss and Starling [12] deliberated the secretion. Marshall and Warren [13] conversed the acid based infection in the twentieth century till the innovative discovery of Helicobacter pylori. Jaworski [14] worked on the numerous observations of bacterial populations in intestinal juice.

\subsection{Mathematical Representation of Nonlinear Stomach Model}

The nervous stomach model is represented with three classes, i.e., Tension $(T)$, Food $(F)$ and Medicine $(M)$ that form a nonlinear TFM system as follows [15]:
$\left\{\begin{array}{lr}T^{\prime}(\Omega)=-b T(\Omega) F(\Omega)-a, & T(0)=i_{1}, \\ F^{\prime}(\Omega)=c T(\Omega)+\mathrm{d} F(\Omega) M(\Omega), & F(0)=i_{2}, \\ M^{\prime}(\Omega)=-c T(\Omega)+a M(\Omega) F(\Omega)-\delta, & M(0)=i_{3} .\end{array}\right.$

where tension $(T)$, food $(F)$ and medicine $(M)$ are dependent variables or classes, while $\Omega$ is the independent variable. In addition, the detail description of the nonlinear TFM system together with the parameter description is provided as follows:

- Tension $T(\Omega)$ : There are various physical properties of nervous stomach, one of the most significant indication is performance under stressed. The nervous form of the stomach is mainly challenging for the human's structure that does not tolerate to complete the developments due to stress.

- Food $F(\Omega)$ : Influence of food on stomach disturbance. The oilier and spicy items of food may play a vital role to disturb the stomach. While food in the form of fruits and vegetable with reasonable oil and spicy ingredient may helpful to reduce the disturbance in the process of the stomach.

- Medicine $M(\Omega)$ : The medication excess can play an active role to disturb the stomach. The high potency medicines are implemented to progress the minor infections that cause the stomach's abnormality.

The necessary information of the parameters is given in Table 1, while further elaborative details can be seen in [15].

\subsection{Related Studies and Problem Statement}

The variety of artificial intelligence (AI)-based computing paradigm have been introduced by the research community for solving stiff, highly nonlinear and singular models governed with PDEs and ODEs as well as their systems with applications in broad domains of applied science and technology. Thus, the motivation of the present work is to investigate in AI based computational intelligence methodologies to study the dynamics of TFM nonlinear system using the structure of Mayer wavelet neural networks (MWNNs) for

Table 1 Parameters explanation in the TFM nonlinear systembased nervous stomach model

\begin{tabular}{ll}
\hline Parameters & Description \\
\hline$d$ & Recovery rate \\
$a$ & Sleep factor \\
$\delta$ & Death rate \\
$c$ & Tension rate \\
$b$ & Food quality \\
$i_{j}, j=1,2,3$ & Initial conditions \\
\hline
\end{tabular}


the modeling of the system along with the global search ability of genetic algorithm (GA) and local search competence of active-set algorithms (ASAs), i.e., MWNN-GA-ASAs. The recent and relevant studies of such type of stochastic computational paradigm have been exploited to solve numerous nonlinear models, e.g., singular models of higher order represented with Lane-Emden equations [16-18], Bouc-Wen hysteresis model for piezostage actuator [19], nonlinear Falkner-Skan systems [20], a fractional form of the singular models [21, 22], fluid mechanics problems [23-25], nonlinear dynamics of the prey-predator system [26], nonlinear electric circuits [27], nonlinear mosquito release model [28], atomic physics models [29], doubly singular systems [30, 31], multi-objective PWR core loading pattern optimization [32], optimal reactive power dispatch [33] and dengue fever system [34]. Keeping in view of these valuable reported studies, the authors are interested to solve the TFM nonlinear model by exploiting MWNN-GA-ASAs based stochastic numerical computing.

\subsection{The Contribution and Insights}

The novel contributions of the design MWNN-GA-ASAs based stochastic scheme are briefly provided as follows:

- A nonlinear TFM differential model is successfully presented through the competency of computational paradigm consist of Mayer Wavelet neural networks
(MWNNs) modeling and trained with hybrid heuristics of GAs aided with ASAs for rapid refinements.

- Stable, reliable and consistent results with good agreement with reference numerical outcomes of the TFM nonlinear system authenticate the worth of the designed computational procedure of MWNN-GA-ASAs.

- The authorization of performance is perceived using different statistical assessment procedures to solve the TFM nonlinear system via multiple executions of computational paradigm of MWNN-GA-ASAs.

- Beside efficient performance of MWNN-GA-ASAs to solve the TFM nonlinear system, other perks include ease in understanding, smooth implementation, extendibility and wider applicability.

\section{Methodology}

The present study is related to solve a TFM-based nonlinear system using the designed computational form of the MWNN-GA-ASAs in two segments, an error-based fitness/ objective function is designed while in second segment, the necessary hybridization steps of GA-ASAs are presented.

\subsection{Designed Procedure of the Networks}

The mathematical representations of the TFM nonlinear system are provided with three classes, i.e., Food, Medicine and Tension, in neural network terminology as follows:

$[\hat{T}(\Omega), \hat{F}(\Omega), \hat{M}(\Omega)]=\left[\begin{array}{l}\sum_{k=1}^{j} u_{T, k} f\left(w_{T, k} \Omega+r_{T, k}\right), \sum_{k=1}^{j} u_{F, k} f\left(w_{F, k} \Omega+r_{F, k}\right), \\ \sum_{k=1}^{j} u_{M, k} f\left(w_{M, k} \Omega+r_{M, k}\right),\end{array}\right]$,

while the first derivative representation of (2) is given as follows:

$\left[\hat{T}^{\prime}(\Omega), \hat{F}^{\prime}(\Omega), \hat{M}^{\prime}(\Omega)\right]=\left[\begin{array}{l}\sum_{k=1}^{j} u_{T, k} f\left(w_{T, k} \Omega+r_{T, k}\right), \sum_{k=1}^{j} u_{F, k} f\left(w_{F, k} \Omega+r_{F, k}\right), \\ \sum_{k=1}^{j} u_{M, k} f\left(w_{M, k} \Omega+r_{M, k}\right),\end{array}\right]$. 
The unknown weight vector $\boldsymbol{W}$ is written as follows:

$\boldsymbol{W}=\left[\boldsymbol{W}_{T}, \boldsymbol{W}_{F}, \boldsymbol{W}_{M}\right]$, for $\boldsymbol{W}_{T}=\left[\boldsymbol{u}_{T}, \boldsymbol{\omega}_{T}, \boldsymbol{r}_{T}\right], \boldsymbol{W}_{F}=\left[\boldsymbol{u}_{F}, \boldsymbol{\omega}_{F}, \boldsymbol{r}_{F}\right]$, and $\boldsymbol{W}_{M}=\left[\boldsymbol{u}_{M}, \boldsymbol{\omega}_{M}, \boldsymbol{r}_{M}\right]$, where where $\hat{T}_{k}=T\left(\Omega_{k}\right), \hat{F}_{k}=F\left(\Omega_{k}\right), \hat{M}_{k}=M\left(\Omega_{k}\right), \quad N h=1$, and $\Omega_{k}=h k . \hat{T}_{k}, \hat{F}_{k}$ and $\hat{M}_{k}$ indicate the proposed approximate solutions representation in MWNN models of the tension

$u_{T}=\left[u_{T, 1}, u_{T, 2}, u_{T, 3}, \ldots, u_{T, m}\right], \quad u_{F}=\left[u_{F, 1}, u_{F, 2}, u_{F, 3}, \ldots, u_{F, m}\right] \quad u_{M}=\left[u_{M, 1}, u_{M, 2}, u_{M, 3}, \ldots, u_{M, m}\right]$,

$\boldsymbol{w}_{T}=\left[w_{T, 1}, w_{T, 2}, \ldots, w_{T, m}\right], \quad \boldsymbol{w}_{F}=\left[w_{F, 1}, w_{F, 2}, \ldots, w_{F, m}\right], \quad \boldsymbol{w}_{M}=\left[w_{M, 1}, w_{M, 2}, \ldots, w_{M, m}\right]$,

$r_{T}=\left[r_{T, 1}, r_{T, 2}, r_{T, 3} \ldots, r_{T, m}\right], \quad r_{F}=\left[r_{F, 1}, r_{F, 2}, r_{F, 3} \ldots, r_{F, m}\right], \quad r_{M}=\left[r_{M, 1}, r_{M, 2}, r_{M, 2}, \ldots, r_{M, m}\right]$.

An error-based fitness/objective function is constructed using differential equation models of MWNNs by exploiting Morlet wavelet activation kernel $f(\Omega)=\cos (1.75 \Omega) e^{-0.5 \Omega^{2}}$ in the hidden layer then the updated networks (2) along with first derivative approximation of the terms in TFM nonlinear system (1) are given as follows [35]: class, food class and medicine class, respectively. While, the expressions (5), (6) and (7) represent the objective functions $E_{\mathrm{Fit} \mathrm{-}}, E_{\mathrm{Fit}-2}$, and $E_{\mathrm{Fit}-3}$ of first, second and third equations of the TFM-based nonlinear system (1), respectively, and expression (8) represents an objective function $E_{\mathrm{Fit}-4}$ linked with the initial conditions of TFM (1). To imple-

$\hat{T}(\Omega), \hat{F}(\Omega), \hat{M}(\Omega) t=\left[\begin{array}{l}\sum_{k=1}^{j} u_{T, k} \cos \left(1.75\left(w_{T, k} \Omega+r_{T, k}\right)\right) e^{-0.5\left(w_{T, k} \Omega+r_{T, k}\right)^{2}}, \\ \sum_{k=1}^{j} u_{F, k} \cos \left(1.75\left(w_{F, k} \Omega+r_{F, k}\right)\right) e^{-0.5\left(w_{F, k} \Omega+r_{F, k}\right)^{2}}, \\ \sum_{k=1}^{j} u_{M, k} \cos \left(1.75\left(w_{M, k} \Omega+r_{M, k}\right)\right) e^{-0.5\left(w_{M, k} \Omega+r_{M, k}\right)^{2}},\end{array}\right]$
$[\hat{T}(\Omega), \hat{F}(\Omega), \hat{M}(\Omega)]=\frac{\mathrm{d}}{\mathrm{d} \Omega}\left[\begin{array}{l}\sum_{k=1}^{j} u_{T, k} \cos \left(1.75\left(w_{T, k} \Omega+r_{T, k}\right)\right) e^{-0.5\left(w_{T, k} \Omega+r_{T, k}\right)^{2}}, \\ \sum_{k=1}^{j} u_{F, k} \cos \left(1.75\left(w_{F, k} \Omega+r_{F, k}\right)\right) e^{-0.5\left(w_{F, k} \Omega+r_{F, k}\right)^{2}}, \\ \sum_{k=1}^{j} u_{M, k} \cos \left(1.75\left(w_{M, k} \Omega+r_{M, k}\right)\right) e^{-0.5\left(w_{M, k} \Omega+r_{M, k}\right)^{2}},\end{array}\right]$

An mean square error function $E_{F i t}$ is presented as follows:

$E_{\mathrm{Fit}}=E_{\mathrm{Fit}-1}+E_{\mathrm{Fit}-2}+E_{\mathrm{Fit}-3}+E_{\mathrm{Fit}-4}$

$E_{\mathrm{Fit}-1}=\frac{1}{N} \sum_{k=1}^{N}\left[\hat{T}_{k}^{\prime}+b \hat{F}_{k} \hat{T}_{k}+a\right]^{2}$

$E_{\mathrm{Fit}-2}=\frac{1}{N} \sum_{k=1}^{N}\left[\hat{F}_{k}^{\prime}-d \hat{T}_{k}-c \hat{M}_{k} \hat{F}_{k}\right]^{2}$

$E_{\text {Fit-3 }}=\frac{1}{N} \sum_{k=1}^{N}\left[\hat{M}_{k}^{\prime}+d \hat{T}_{k}-b \hat{F}_{k} \hat{M}_{k}+\delta\right]^{2}$,

$E_{\mathrm{Fit}-4}=\frac{1}{3}\left[\left(\hat{T}_{0}-r_{1}\right)^{2}+\left(\hat{F}_{0}-r_{2}\right)^{2}+\left(\hat{M}_{0}-r_{3}\right)^{2}\right]$, ment the design MWNNs, one need to optimize $E_{\mathrm{Fit}}$ such that $E_{\mathrm{Fit}} \rightarrow 0$ with the availability of weights of MWNNs trained by appropriate optimization mechanism with on prior requirement of the dataset for training, testing and validation as required in traditionally supervised neural networks.

\subsection{Optimization: MWNN-GA-ASAs}

The necessary overview of the optimization scheme adopted for training of MWNNs based objective function for nonlinear TFM system using the designed integrated computational heuristics GA-ASAs is provided in this section.

GAs are considered to be one the premier global search procedure of optimization implemented to solve many renewed problems of the linear/nonlinear systems. GA can be implemented to solve both optimization systems with constrained and unconstrained forms is different domain since their introduction in early seventies of last century. GAs are typically exploited the global search to find the 
Table 2 Optimization procedures via MWNN-GAASAs for the TFM nonlinear system

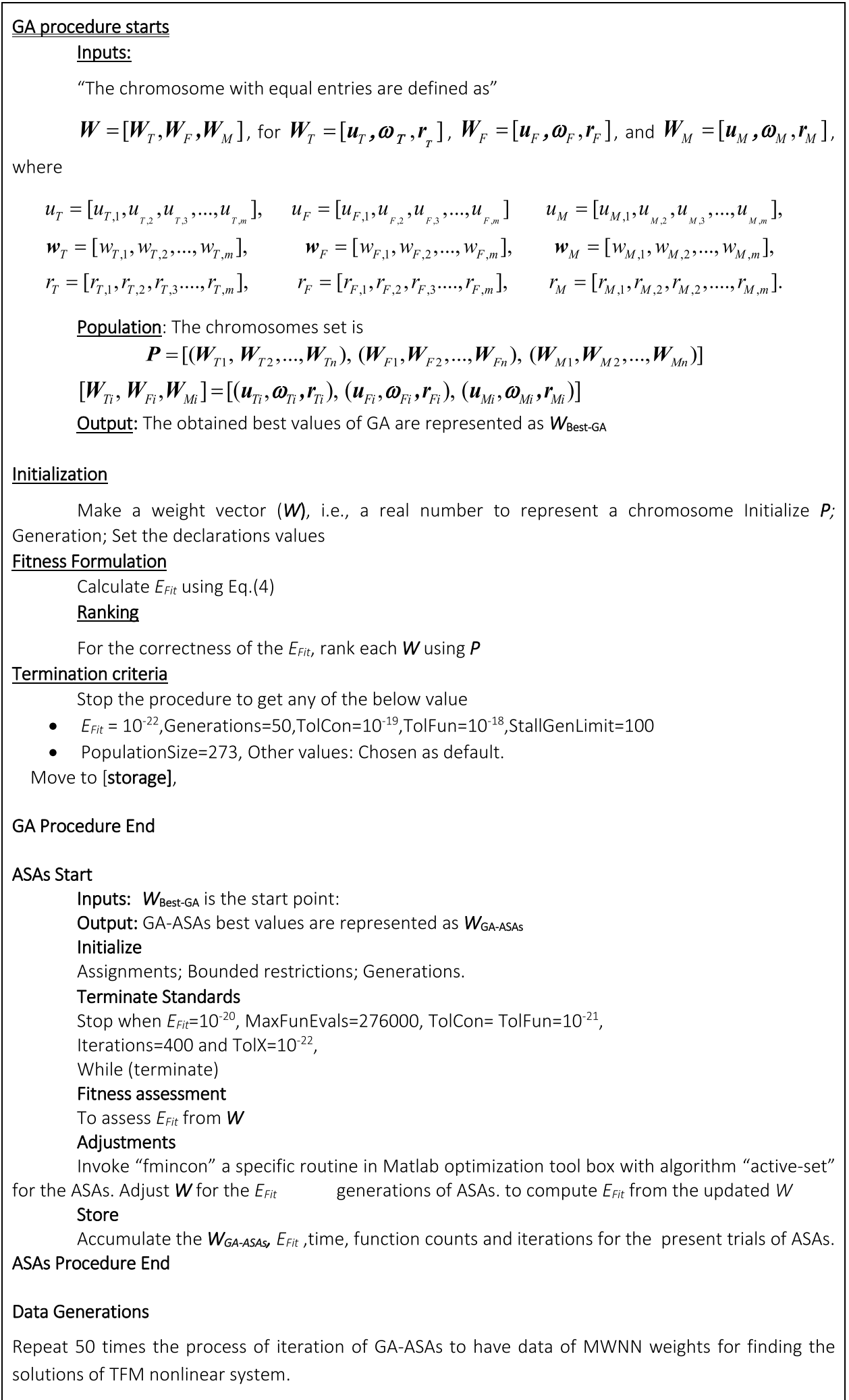

candidate solutions by modifying population at each generation through reproduction operators of crossover, mutations and selection. In recent years, GA is particularly implemented in optimization problems in the hospitalization outflow models [36], brain tumor images [37], optimization of layer thickness in multilayer piezoelectric 
transducer [38], economic load dispatch problems [39], nonlinear Falkner-Skan systems [40], prediction differential system [41], optimization steps of cloud service [42], periodic model [43], monorail vehicle dynamics [44] and nonlinear electric circuit models [45]. The performance or optimization strength of GAs is further enhanced with the combination of local search procedure.

Active set algorithms (ASA) are a local search optimization mechanics generally applied to solve both form of the constrained/unconstrained optimization tasks/models. ASAs are well-organized optimization methods used to compute the results competently. In recent few decades, ASAs are implemented for OPF problem in DC grids [46], optimum stockpile and period length [47], continuum structures subjected to harmonic force excitation [48], dynamic positioning of marine [49] and transient heat conduction problem [50].

Therefore, it is presented study, the process of training of weights of MWNNs is accomplished with the knacks of hybrid heuristics of GA-ASAs. The pseudocode of GAASAs is provided in the Table 2 with necessary parameter settings and details of procedural steps for both GAs and ASAs.

\subsection{Performance Processes}

The statistical performances using the mean absolute deviation (MAD), Theil's inequality coefficient (TIC), variance account for (VAF) and semi interquartile range (S.I.R) along their global illustrations are implemented to solve the TFM nonlinear system and their definitions are shown mathematically as follows:

$$
\begin{aligned}
& {\left[\mathrm{MAD}_{T}, \mathrm{MAD}_{F}, \mathrm{MAD}_{M}\right]} \\
& \quad=\left[\sum_{k=1}^{v}\left|T_{k}-\hat{T}_{k}\right|, \sum_{k=1}^{v}\left|F_{k}-\hat{F}_{k}\right|, \sum_{k=1}^{v}\left|M_{k}-\hat{M}_{k}\right|\right],
\end{aligned}
$$

$\left\{\begin{array}{l}\text { S.I.R }=-\frac{1}{2} \times\left(Q_{1}-Q_{3}\right), \\ Q_{1}=1 \text { st quartile and } Q_{3}=3 \text { rd quartile, }\end{array}\right.$

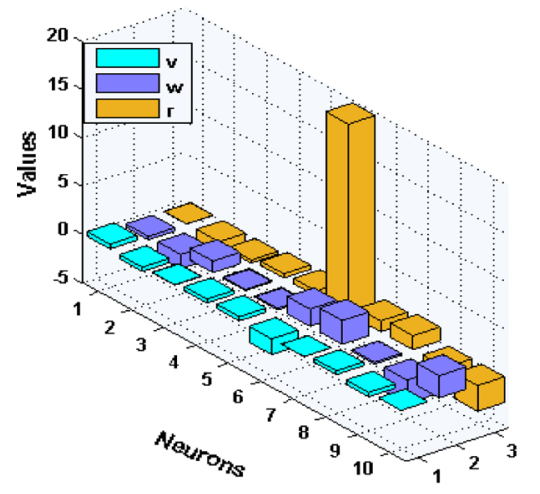

(a) Best weights of $T(\Omega)$

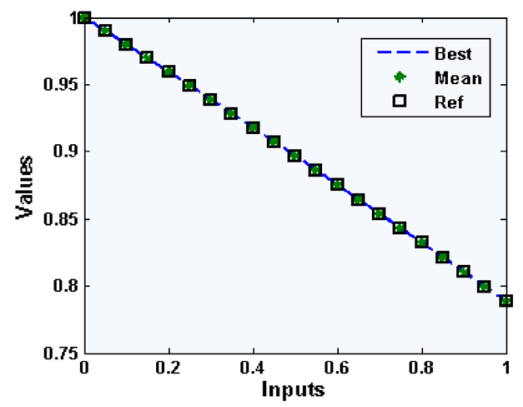

(d) Comparison for $T(\Omega)$ class

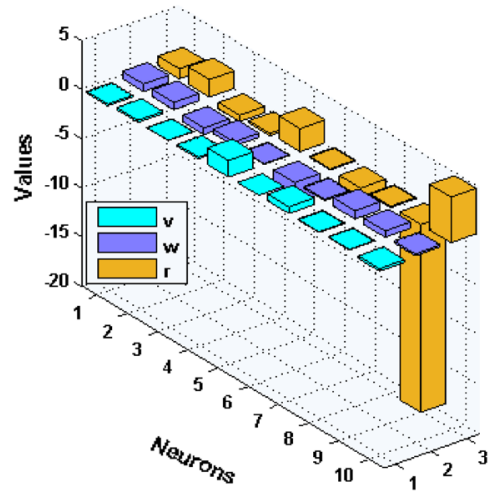

(b) Best weights of $F(\Omega)$

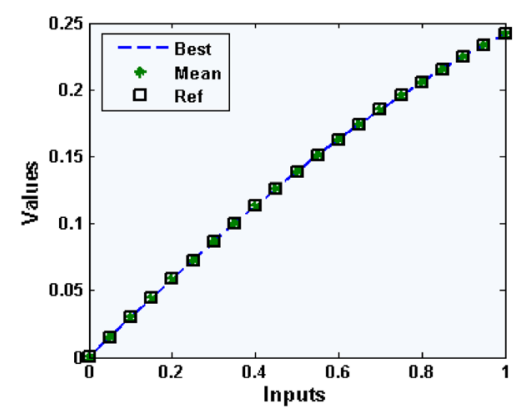

(e) Comparison for the $F(\Omega)$ class

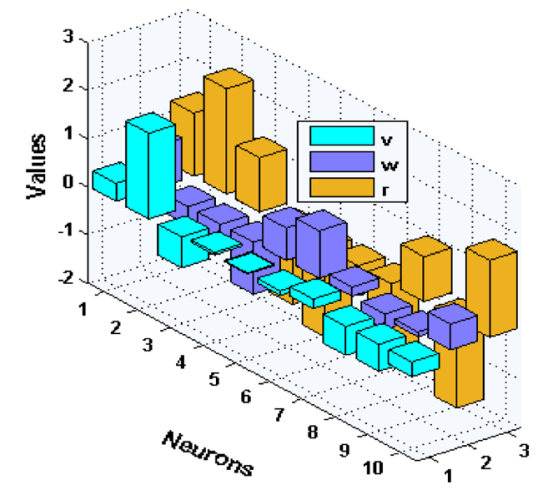

(c) Best weights of $M(\Omega)$

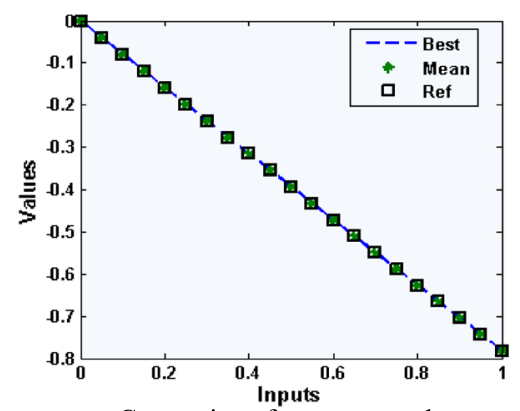

(f) Comparison for $M(\Omega)$ class

Fig. 1 Best weights and results comparison to solve the TFM nonlinear system based on nervous stomach model 
$\left\{\begin{array}{l}{\left[\mathrm{VAF}_{T}, \mathrm{VAF}_{F}, \mathrm{VAF}_{M}\right]=\left[\begin{array}{l}\left(1-\frac{\operatorname{var}\left(T_{k}-\hat{T}_{k}\right)}{\operatorname{var}\left(T_{k}\right)}\right) * 100,\left(1-\frac{\operatorname{var}\left(F_{k}-\hat{F}_{k}\right)}{\operatorname{var}\left(F_{k}\right)}\right) * 100, \\ \left(1-\frac{\operatorname{var}\left(M_{k}-\hat{M}_{k}\right)}{\operatorname{var}\left(M_{k}\right)}\right) * 100,\end{array}\right]} \\ {\left[\mathrm{EVAF}_{T}, \mathrm{EVAF}_{F}, \mathrm{EVAF}_{M}\right]=\left[\left|100-\mathrm{VAF}_{T}, 100-\mathrm{VAF}_{F}, 100-\mathrm{VAF}_{M}\right|\right] .}\end{array}\right.$

$\left[\mathrm{TIC}_{T}, \operatorname{TIC}_{F}, \mathrm{TIC}_{M}\right]=\left[\begin{array}{l}\frac{\sqrt{\frac{1}{v} \sum_{k=1}^{v}\left(T_{k}-\hat{T}_{k}\right)^{2}}}{\left(\sqrt{\frac{1}{v} \sum_{k=1}^{v} \hat{T}_{k}^{2}}+\sqrt{\frac{1}{v} \sum_{k=1}^{v} \hat{T}_{k}^{2}}\right)}, \frac{\sqrt{\frac{1}{v} \sum_{k=1}^{v}\left(F_{k}-\hat{F}_{k}\right)^{2}}}{\left(\sqrt{\frac{1}{v} \sum_{k=1}^{v} F_{k}^{2}}+\sqrt{\frac{1}{n} \sum_{k=1}^{n} \hat{F}_{k}^{2}}\right)}, \\ \frac{\sqrt{\frac{1}{v} \sum_{k=1}^{v}\left(M_{k}-\hat{M}_{k}\right)^{2}}}{\left(\sqrt{\frac{1}{v} \sum_{k=1}^{v} \hat{M}_{k}^{2}}+\sqrt{\frac{1}{v} \sum_{k=1}^{v} \hat{M}_{k}^{2}}\right)},\end{array}\right]$,

where the approximate solutions of TFM nonlinear model are portrayed with $\hat{T}, \hat{F}$ and $\hat{M}$.

\section{Simulation of the Results}

The TFM nonlinear system given in Eq. (1) is numerically studied using the designed integrated heuristics of MWNNGA-ASAs and its performance is presented in this section. The results obtained form MWNN-GA-ASAs for the TFM nonlinear system are compared with the Adams numerical solutions, which are calculated as per procedure and setting reported in [51, 52]. The results of MWNN-GA-ASAs are also described through convergence analysis, $\mathrm{AE}$ and performance indices elaborately in this section to access the accurate performance.

The simplified mathematical form of the TFM nonlinear system (1) using appropriate parameters is given as [15]:

$$
\left\{\begin{array}{lc}
T^{\prime}(\Omega)=-0.1 T(\Omega) F(\Omega)-0.2, & T(0)=0.9999, \\
F^{\prime}(\Omega)=0.3 T(\Omega)+0.4 F(\Omega) M(\Omega), & F(0)=0.0001, \\
M^{\prime}(\Omega)=0.2 M(\Omega) F(\Omega)-0.3 T(\Omega)-0.5, & M(0)=0,
\end{array}\right.
$$

An error function based on TFM nonlinear system (13) becomes as follows:

$$
\begin{aligned}
E_{\mathrm{Fit}} & =\frac{1}{N} \sum_{k=1}^{N}\left(\begin{array}{l}
{\left[\hat{T}_{k}^{\prime}+0.2+0.1 \hat{T}_{k} \hat{F}_{k}\right]^{2}+\left[\hat{F}_{k}-0.4 \hat{F}_{k} \hat{M}_{k}-0.3 \hat{T}_{k}\right]^{2}} \\
+\left[\hat{M}_{k}-0.2 \hat{F}_{k} \hat{M}_{k}+0.3 \hat{T}_{k}+0.5\right]^{2}
\end{array}\right) \\
& +\frac{1}{3}\left[\left(\hat{T}_{0}-\frac{9999}{10000}\right)^{2}+\left(\hat{F}_{0}-\frac{1}{10000}\right)^{2}+\left(\hat{M}_{0}\right)^{2}\right] .
\end{aligned}
$$

The design MWNN models of differential equation for the TFM nonlinear system representing the dynamics of nervous stomach based on 30 variables or 10 neurons is solved by computational procedure of integrated heuristics of GA-ASAs are per details and procedure steps given in the last section. The mathematical expression based outcomes of best performing weight vectors are given below to solve the TFM nonlinear system as:

$$
\begin{aligned}
\hat{T}(\Omega)= & 0.4897 \cos (1.75(-0.3447 \Omega-0.0207)) e^{-0.5(-0.3447 \Omega-0.0207)^{2}}-0.4283 \cos (1.75(-1.4490 \Omega-1.7481)) e^{-0.5(-1.4490 \Omega-1.7481)^{2}} \\
& +0.0395 \cos (1.75(1.1878 \Omega-0.2979)) e^{-0.5(1.1878 \Omega-0.2979)^{2}}-0.4092 \cos (1.75(0.1054 \Omega+0.4437)) e^{-0.5(0.1054 \Omega+0.4437)^{2}} \\
& +0.4375 \cos (1.75(-0.1424 \Omega+0.5180)) e^{-0.5(-0.1424 \Omega+0.5180)^{2}}-1.6351 \cos (1.75(1.7891 \Omega+19.5928)) e^{-0.5(1.7891 \Omega+19.5928)^{2}} \\
& +0.0158 \cos (1.75(2.4490 \Omega-1.1238)) e^{-0.5(2.4490 \Omega-1.1238)^{2}}+0.3890 \cos (1.75(-0.1919 \Omega+1.4408)) e^{-0.5(-0.1919 \Omega+1.4408)^{2}} \\
& -0.4496 \cos (1.75(-2.4314 \Omega-2.8338)) e^{-0.5(-2.4314 \Omega-2.8338)^{2}}+0.00115 \cos (1.75(2.2997 \Omega-2.6641)) e^{-0.5(2.2997 \Omega-2.6641)^{2}}
\end{aligned}
$$




$$
\begin{aligned}
\hat{F}(\Omega)= & -0.1671 \cos (1.75(+0.7516 \Omega+0.0162)) e^{-0.5(0.7516 \Omega+0.0162)^{2}}+0.2086 \cos (1.75(+0.7330 \Omega+1.7661)) e^{-0.5(0.7330 \Omega+1.7661))^{2}} \\
& +0.0380 \cos \left(1.75(+0.6751 \Omega-0.65023) e^{-0.5(0.6751 \Omega-0.65023)^{2}}+0.1819 \cos (1.75(+0.4320 \Omega-0.2384)) e^{-0.5(0.4320 \Omega-0.2384)^{2}}\right. \\
& +1.6750 \cos (1.75(+0.0702 \Omega+2.3342)) e^{-0.5(0.0702 \Omega+2.3342)^{2}}-3.7087 \cos (1.75(-2.0942 \Omega+0.1007)) e^{-0.5(-2.0942 \Omega+0.1007)^{2}} \\
& +0.674308 \cos (1.75(+0.1474 \Omega-0.9128)) e^{-0.5(+0.1474 \Omega-0.9128)^{2}}-0.0769 \cos (1.75(+0.8456 \Omega-0.1273)) e^{-0.5(+0.8456 \Omega-0.1273)^{2}} \\
& +0.0572 \cos (1.75(+0.6432 \Omega-19.0622)) e^{-0.5(+0.6432 \Omega-19.0622)^{2}}-0.2633 \cos (1.75(+0.1823 \Omega+4.6308)) e^{-0.5(+0.1823 \Omega+4.6308)^{2}},
\end{aligned}
$$

$$
\begin{aligned}
\hat{M}(\Omega)= & 0.3722 \cos (1.75(0.8749 \Omega+1.3102)) e^{-0.5(0.8749 \Omega+1.3102)^{2}}+1.7790 \cos (1.75(-0.3788 \Omega+2.1888)) e^{-0.5(-0.3788 \Omega+2.1888)^{2}} \\
& -0.6340 \cos (1.75(-0.4096 \Omega+1.1256)) e^{-0.5(-0.4096 \Omega+1.1256)^{2}}+0.0477 \cos (1.75(-1.0714 \Omega-1.5411)) e^{-0.5(-1.0714 \Omega-1.5411)^{2}} \\
& -0.0216 \cos (1.75(+0.6682 \Omega-1.8484)) e^{-0.5(+0.6682 \Omega-1.8484)^{2}}-0.0954 \cos (1.75(+0.9770 \Omega-0.6124)) e^{-0.5(+0.9770 \Omega-0.6124)^{2}} \\
& +0.1974 \cos (1.75(+0.1892 \Omega-1.4367)) e^{-0.5(+0.1892 \Omega-1.4367)^{2}}-0.6002 \cos (1.75(-0.3246 \Omega+0.9276)) e^{-0.5(-0.3246 \Omega+0.9276)^{2}} \\
& -0.5587 \cos (1.75(-0.0997 \Omega-18415)) e^{-0.5(-0.0997 \Omega-18415)^{2}}-0.1883 \cos (1.75(+0.6120 \Omega+0.813)) e^{-0.5(+0.61200 \Omega+0.813)^{2}}
\end{aligned}
$$

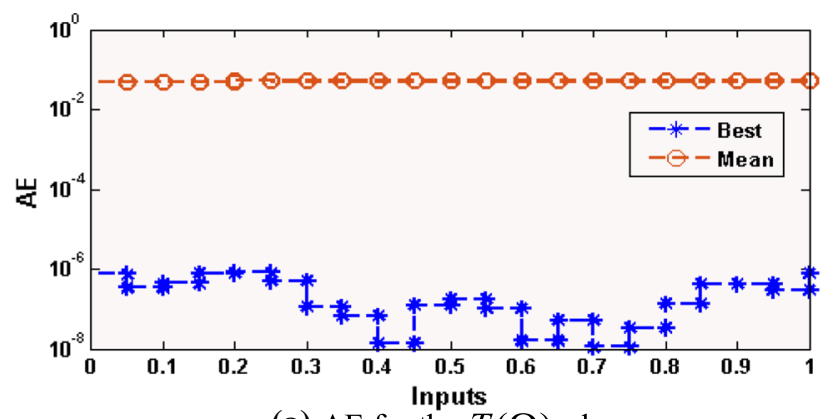

(a) AE for the $T(\Omega)$ class

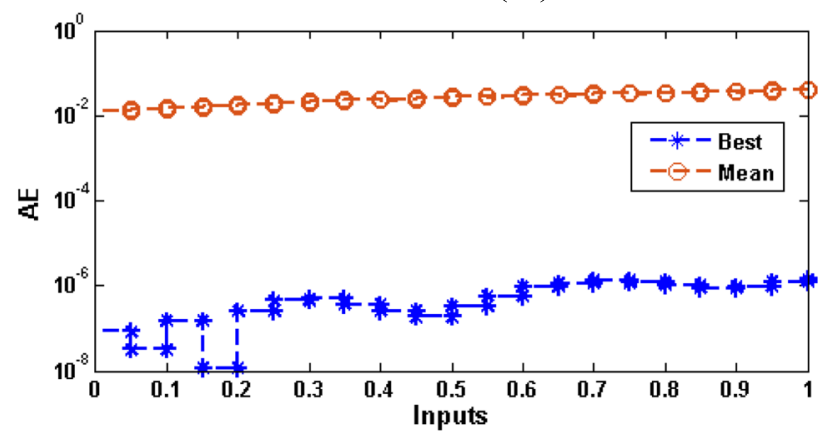

(b) AE for the $F(\Omega)$ class

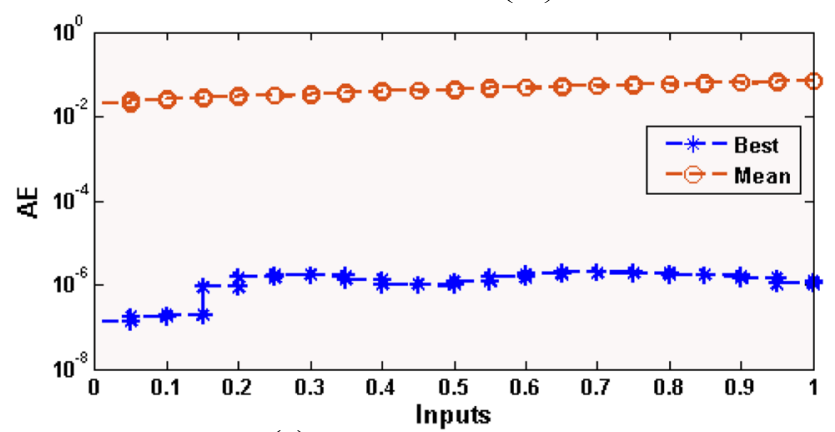

(c) AE for the $M(\Omega)$ class

Fig. 2 AE values of the TFM nonlinear system based on nervous stomach model
The numerical values representation of best weights and approximate solutions to solve the TFM nonlinear model using the MWNN-GA-ASAs are illustrated in Fig. 1. The best weights for the TFM nonlinear system have been provided in Fig. 1a-c using 10 numbers of neurons in MYNNs. The values of these weight vector are used to obtain the above Eqs. (15-17). The result comparisons for each class of the TFM nonlinear system is provided in Fig. 1d-f. The comparative assessment of the mean and best results accomplished through the MWNN-GA-ASAs is performed with the Adams numerical solutions to solve the TFM nonlinear system. The accurate MWNN-GA-ASAs performance is witnessed through the overlapping of the solutions.

The AE plots have been provided in Fig. 2, i.e., in subfigures Fig. 2a-c for the $T(\Omega), F(\Omega)$ and $M(\Omega)$ classes, respectively, of the TFM nonlinear system to access/measure the performance of MWNN-GA-ASAs. The values of the AE are plotted in Fig. 2 for calculation of statistical mean value and best, i.e., with lowest AE for 100 runs of MWNN-GA-ASAs to solve the TEM nonlinear systems. One

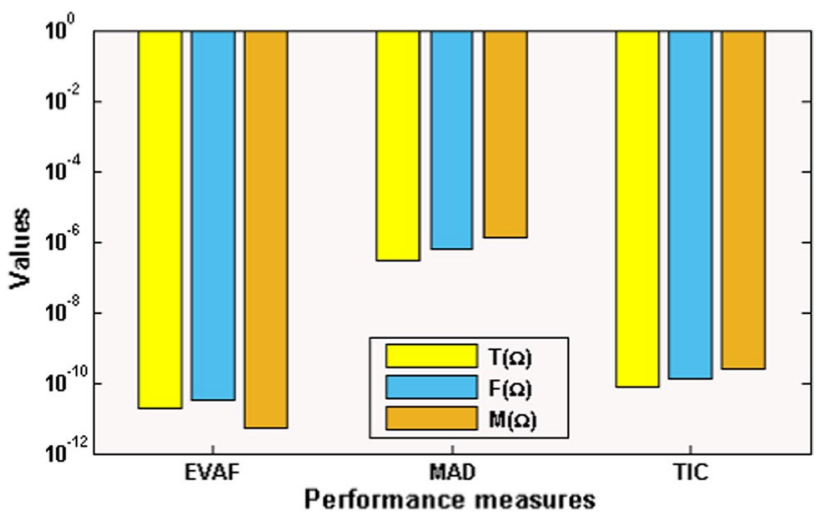

Fig. 3 Performance indices based on EVAF, MAD and TIC operators to solve the nonlinear TFM system based on nervous stomach model 
Fig. 4 TIC operator performances based on ANN-GA-IPA to solve the TFM nonlinear system based on nervous stomach model

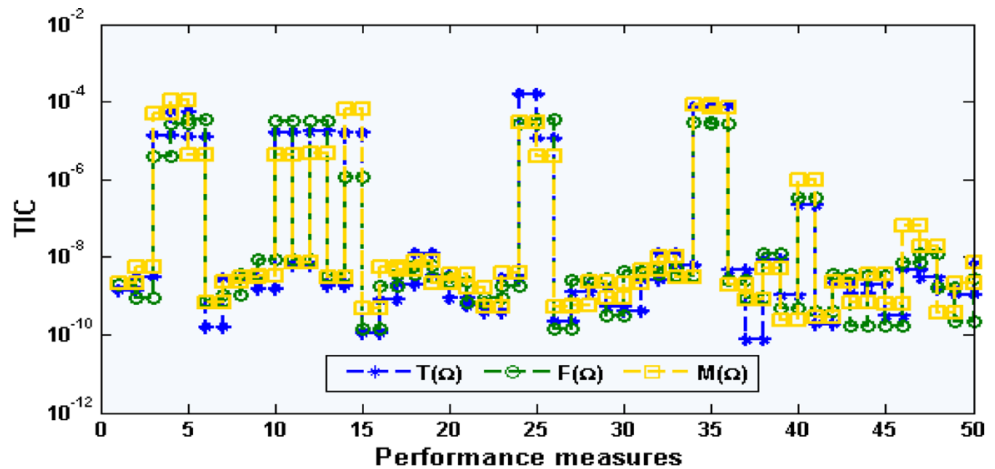

(a) Convergence performance of TIC values

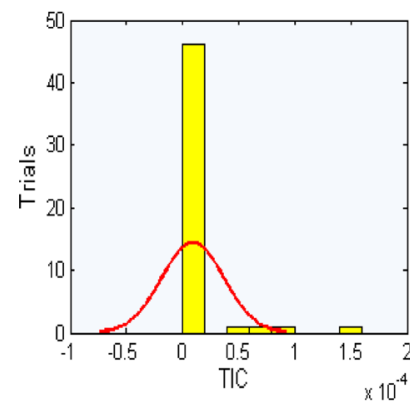

(b) Histograms of $T(\Omega)$ class

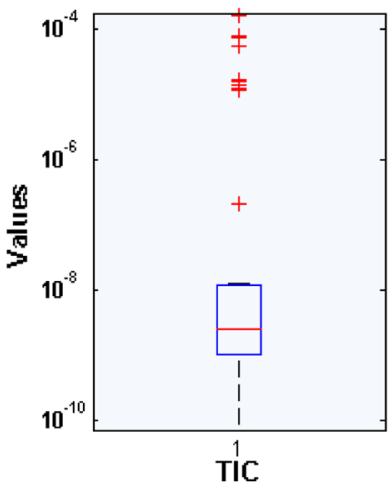

(e) Boxplot for $T(\Omega)$ class

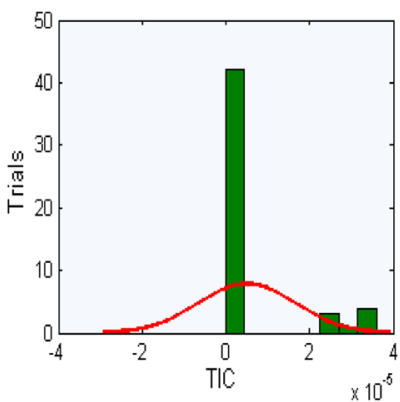

(c) Histograms of $F(\Omega)$ class

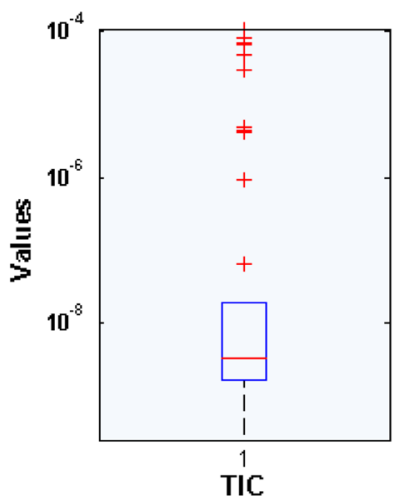

(f) Boxplot for $F(\Omega)$ class

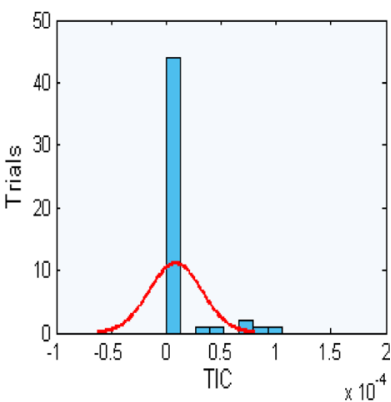

(d) Histograms of $M(\Omega)$ class

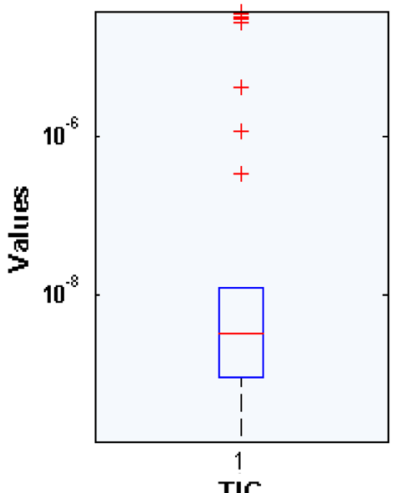

(g) Boxplot for $M(\Omega)$ class can evidently observe that the best values for $T(\Omega), F(\Omega)$ and $M(\Omega)$ classes lie around $10^{-06}-10^{-08}, 10^{-07}-10^{-08}$ and $10^{-06}-10^{-07}$, respectively, while mean performances of $T(\Omega)$, $F(\Omega)$ and $M(\Omega)$ close to $10^{-01}-10^{-02}$. The investigations of the performances based on 'EVAF', 'TIC' and 'MAD' are conducted for the TFM nonlinear system and outcomes are graphically presented in the Fig. 3. One may decipher that for the $T(\Omega), F(\Omega)$ and $M(\Omega)$ categories, the best performances of the EVAF, MAD and TIC gages found around $10^{-10}-10^{-11}, 10^{-06}-10^{-07}$ and $10^{-11}-10^{-12}$, respectively.

The graphical representations of the statistical performance measures together with their analysis on boxplots and histograms are portrayed in Figs. 4, 5 and 6 for MWNN-GAASAs outcomes for TFM nonlinear system. One may see that the TIC operator magnitude for $T(\Omega), F(\Omega)$ and $M(\Omega)$ lie in close vicinity of $10^{-05}-10^{-10}$. The MAD performance index for $T(\Omega), F(\Omega)$ and $M(\Omega)$ lie $10^{-04}-10^{-07}$. Similarly, the EVAF operator magnitudes for $T(\Omega), F(\Omega)$ and $M(\Omega)$ lie around $10^{-08}-10^{-09}$. One can clearly decipher that the convergence and precise performances is observed from all graphical illustration of the TIC, MAD and EVAF used for analysis of the solutions for the TFM nonlinear system via MWNN-GA-ASAs.

For exhaustive analysis of the accuracy and convergence measures, statistical performances based on the standard deviation (SD), median, minimum (Min), S.I.R and maximum (Max) gages are conducted and results are given in Tables 3, 4 and 5 for $T(\Omega), F(\Omega)$ and $M(\Omega)$ of TFM nonlinear system. The Min values represent the best results, which are found around $10^{-07}-10^{-10}$ and the Max operators represents the worst results lie around $10^{-01}-10^{-02}$, the MED, Mean, S.I.R and SD performances lie around $10^{-05}-10^{-06}$, 
Fig. 5 MAD operator performances based on ANN-GA-IPA system based on nervous stomach model to solve the TFM nonlinear

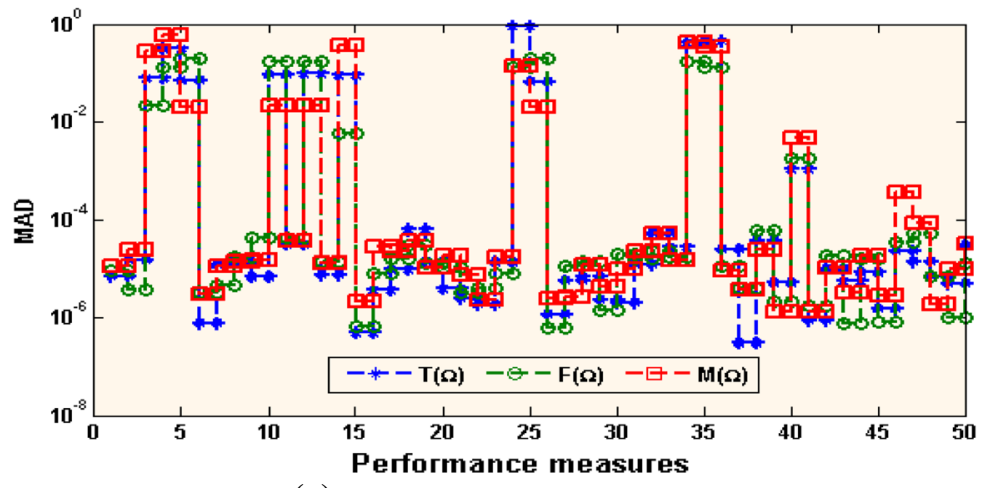

(a) Convergence performance of MAD values

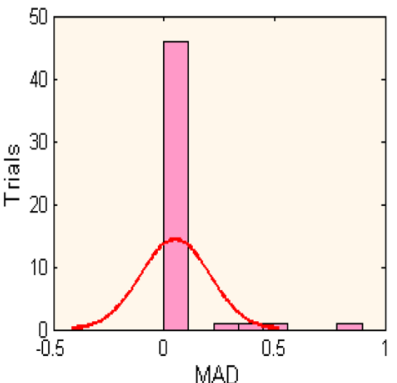

(b) Histograms of $T(\Omega)$ class

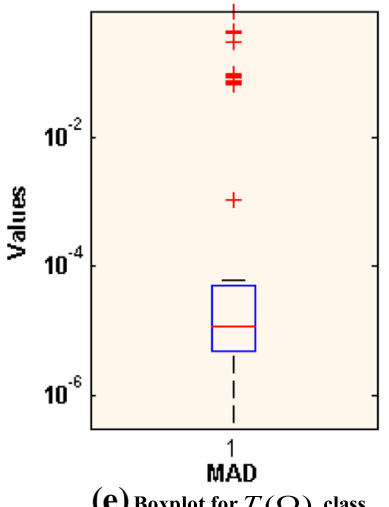

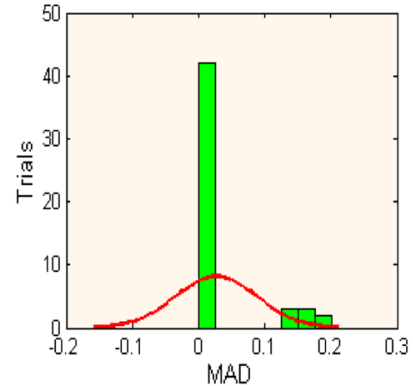

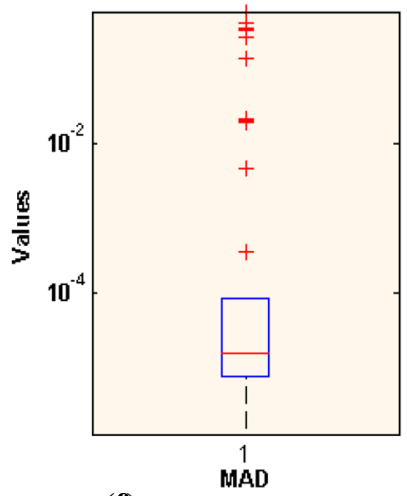

(f) Boxplot for $F(\Omega)$ class (c) Histograms of $F(\Omega)$ class

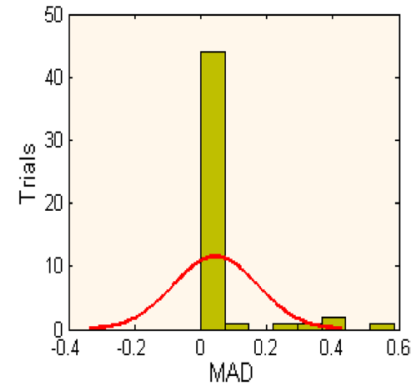

(d) Histograms of $M(\Omega)$ class

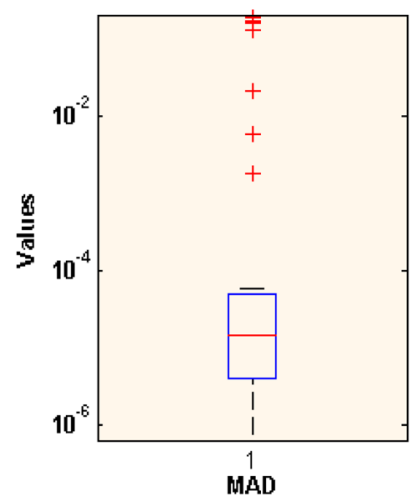

(g) Boxplot for $M(\Omega)$ class
$10^{-02}-10^{-03}, 10^{-05}-10^{-07}$ and $10^{-01}-10^{-02}$, respectively. One can evidently perceive the worth and value of the MWNNGA-ASAs performance base on statistical operators for solving the TFM nonlinear system.

The performance measures on the calculation of global operators including MAD, EVAF and T.I.C for multiple executions based on the proposed MWNN-GA-ASAs are provided in Table 6 for the TFM nonlinear system representing nervous stomach model. The MED values of global TIC, MAD and EVAF magnitudes lie $10^{-05}-10^{-06}, 10^{-09}-10^{-10}$ and $10^{-08}-10^{-09}$, respectively, whereas the global S.I.R operator of TIC, MAD and EVAF lie $10^{-06}-10^{-07}, 10^{-09}-10^{-10}$ and $10^{-08}-10^{-09}$, respectively for TFM nonlinear system.
The close to optimal values of all these global measures G-TIC, G-MAD) and G-EVAF indicate the correctness, precision and efficacy of the integrated computational heuristics of MWNN-GA-ASAs.

\section{Conclusions}

A novel design of the Morlet wavelet neural network is presented to solve the TFM nonlinear system together with the capability of local search ASAs and global search GAs based optimization schemes, i.e., MWNN-GA-ASAs. An error function is presented based on the TFM nonlinear 
Fig. 6 EVAF operator performances based on ANN-GA-IPA to solve the TFM nonlinear system based on nervous stomach model

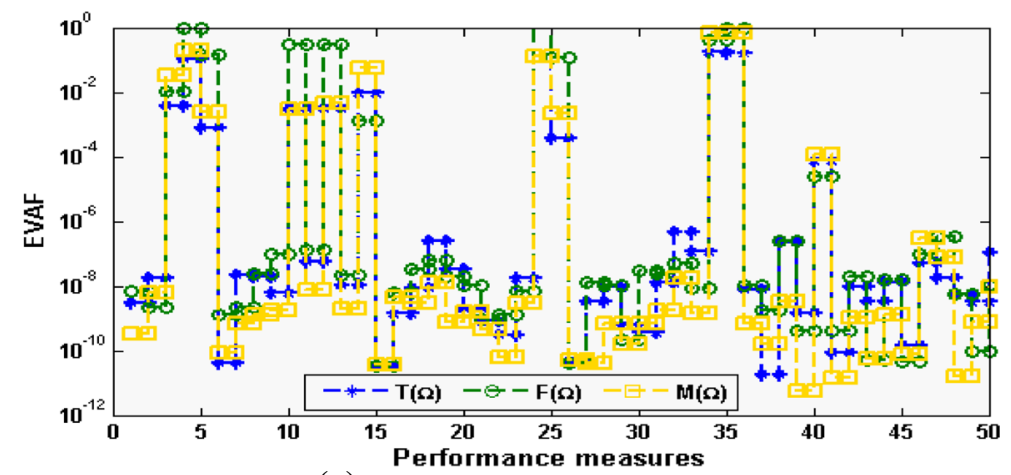

(a) Convergence performance of EVAF values

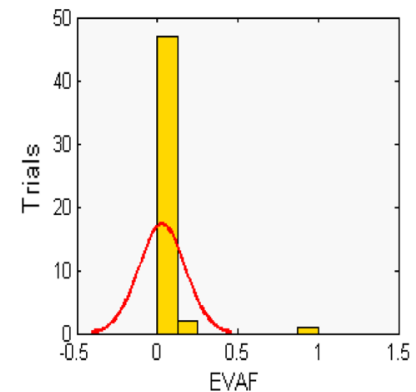

(b) Histograms of $T(\Omega)$ class

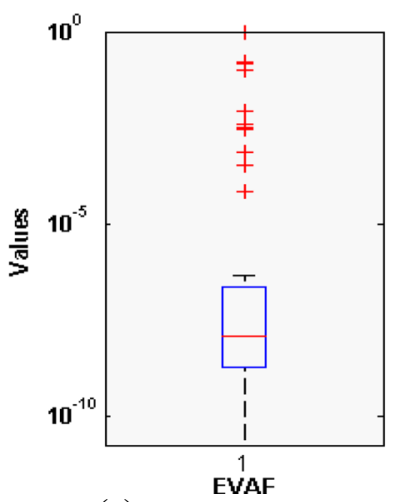

(e) Boxplot for $T(\Omega)$ class

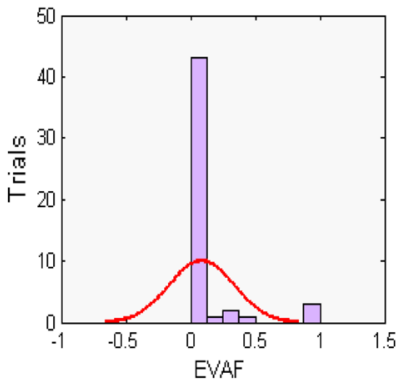

(c) Histograms of $F(\Omega)$ class

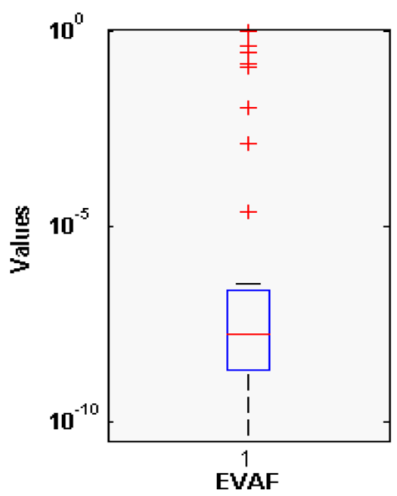

(f) Boxplot for $F(\Omega)$ class

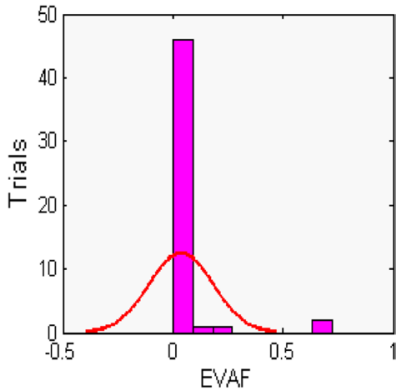

(d) Histograms of $M(\Omega)$ class

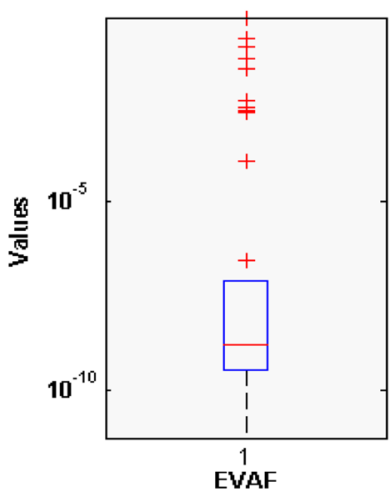

(g) Boxplot for $M(\Omega)$ class differential system, its boundary conditions and then optimization is performed using the capabilities of integrated heuristics of GA-ASAs. The obtained numerical outcomes via MWNN-GA-ASAs are compared with the Adams numerical results that evidently show the precision of the TFM nonlinear differential system with values of the AE lie around $10^{-06}$ to $10^{-08}$. Moreover, the magnitudes of MAD, TIC and EVAF operators verify the performance for solving the TFM nonlinear differential system. The assessments through statistical indicators for multiple independent executions using proposed MWNN-GA-ASAs based on the MED, Min, S.I.R,
Mean, SD and Max operatives authenticate its correctness and worth. Furthermore, close to optimal values of global measures including G-TIC, G-MAD and G-EVAF indicate the correctness, precision and efficacy of the integrated computational heuristics of MWNN-GA-ASAs for solving the TFM nonlinear differential system.

In future, the designed form of the computational MWNN-GA-ASAs is capable to solve the nonlinear systems' biological studies [53-55], financial mathematical models [56, 57] and fluid dynamic models [58-60]. 
Table 3 Statistical demonstrations of the TFM nonlinear system based on nervous stomach model for $T(\Omega)$

\begin{tabular}{lllllll}
\hline$\Omega$ & $T(\Omega)$ & & & & & \\
\cline { 2 - 7 } & MIN & MAX & MED & MEAN & S.I.R & STD \\
\hline 0 & $1.8846 \mathrm{E}-08$ & $9.9990 \mathrm{E}-01$ & $3.5883 \mathrm{E}-06$ & $4.9346 \mathrm{E}-02$ & $1.4794 \mathrm{E}-05$ & $1.6092 \mathrm{E}-01$ \\
0.05 & $2.2642 \mathrm{E}-10$ & $9.8986 \mathrm{E}-01$ & $3.9075 \mathrm{E}-06$ & $4.9710 \mathrm{E}-02$ & $8.9661 \mathrm{E}-06$ & $1.6052 \mathrm{E}-01$ \\
0.1 & $7.0308 \mathrm{E}-08$ & $9.7975 \mathrm{E}-01$ & $4.8363 \mathrm{E}-06$ & $5.0075 \mathrm{E}-02$ & $1.2380 \mathrm{E}-05$ & $1.6014 \mathrm{E}-01$ \\
0.15 & $2.0802 \mathrm{E}-07$ & $9.6957 \mathrm{E}-01$ & $1.0476 \mathrm{E}-05$ & $5.0414 \mathrm{E}-02$ & $1.4149 \mathrm{E}-05$ & $1.5975 \mathrm{E}-01$ \\
0.2 & $2.1967 \mathrm{E}-07$ & $9.5932 \mathrm{E}-01$ & $1.2575 \mathrm{E}-05$ & $5.0721 \mathrm{E}-02$ & $2.0079 \mathrm{E}-05$ & $1.5934 \mathrm{E}-01$ \\
0.25 & $2.8218 \mathrm{E}-07$ & $9.4901 \mathrm{E}-01$ & $1.3800 \mathrm{E}-05$ & $5.0994 \mathrm{E}-02$ & $2.9501 \mathrm{E}-05$ & $1.5892 \mathrm{E}-01$ \\
0.3 & $1.1401 \mathrm{E}-07$ & $9.3863 \mathrm{E}-01$ & $1.4645 \mathrm{E}-05$ & $5.1234 \mathrm{E}-02$ & $3.3119 \mathrm{E}-05$ & $1.5848 \mathrm{E}-01$ \\
0.35 & $6.8677 \mathrm{E}-08$ & $9.2820 \mathrm{E}-01$ & $1.5196 \mathrm{E}-05$ & $5.1440 \mathrm{E}-02$ & $3.0867 \mathrm{E}-05$ & $1.5801 \mathrm{E}-01$ \\
0.4 & $1.3667 \mathrm{E}-08$ & $9.1771 \mathrm{E}-01$ & $1.2826 \mathrm{E}-05$ & $5.1613 \mathrm{E}-02$ & $2.7474 \mathrm{E}-05$ & $1.5751 \mathrm{E}-01$ \\
0.45 & $1.1141 \mathrm{E}-07$ & $9.0716 \mathrm{E}-01$ & $7.5459 \mathrm{E}-06$ & $5.1753 \mathrm{E}-02$ & $3.5612 \mathrm{E}-05$ & $1.5697 \mathrm{E}-01$ \\
0.5 & $1.7964 \mathrm{E}-07$ & $8.9656 \mathrm{E}-01$ & $1.0214 \mathrm{E}-05$ & $5.1859 \mathrm{E}-02$ & $4.1312 \mathrm{E}-05$ & $1.5639 \mathrm{E}-01$ \\
0.55 & $1.0213 \mathrm{E}-07$ & $8.8592 \mathrm{E}-01$ & $9.6724 \mathrm{E}-06$ & $5.1930 \mathrm{E}-02$ & $4.3751 \mathrm{E}-05$ & $1.5577 \mathrm{E}-01$ \\
0.6 & $1.5993 \mathrm{E}-08$ & $8.7523 \mathrm{E}-01$ & $9.7770 \mathrm{E}-06$ & $5.1965 \mathrm{E}-02$ & $4.2141 \mathrm{E}-05$ & $1.5510 \mathrm{E}-01$ \\
0.65 & $5.0884 \mathrm{E}-08$ & $8.6450 \mathrm{E}-01$ & $1.0151 \mathrm{E}-05$ & $5.1962 \mathrm{E}-02$ & $3.6176 \mathrm{E}-05$ & $1.5438 \mathrm{E}-01$ \\
0.7 & $1.1051 \mathrm{E}-08$ & $8.5372 \mathrm{E}-01$ & $8.8554 \mathrm{E}-06$ & $5.1921 \mathrm{E}-02$ & $2.7578 \mathrm{E}-05$ & $1.5360 \mathrm{E}-01$ \\
0.75 & $3.3095 \mathrm{E}-08$ & $8.4292 \mathrm{E}-01$ & $7.0654 \mathrm{E}-06$ & $5.1839 \mathrm{E}-02$ & $2.3591 \mathrm{E}-05$ & $1.5275 \mathrm{E}-01$ \\
0.8 & $1.2570 \mathrm{E}-07$ & $8.3208 \mathrm{E}-01$ & $8.9146 \mathrm{E}-06$ & $5.1719 \mathrm{E}-02$ & $2.3378 \mathrm{E}-05$ & $1.5185 \mathrm{E}-01$ \\
0.85 & $8.2978 \mathrm{E}-08$ & $8.2121 \mathrm{E}-01$ & $1.0648 \mathrm{E}-05$ & $5.1559 \mathrm{E}-02$ & $2.0628 \mathrm{E}-05$ & $1.5089 \mathrm{E}-01$ \\
0.9 & $2.5847 \mathrm{E}-07$ & $8.1031 \mathrm{E}-01$ & $1.0993 \mathrm{E}-05$ & $5.1359 \mathrm{E}-02$ & $2.1787 \mathrm{E}-05$ & $1.4986 \mathrm{E}-01$ \\
0.95 & $2.9054 \mathrm{E}-07$ & $7.9939 \mathrm{E}-01$ & $1.3039 \mathrm{E}-05$ & $5.1119 \mathrm{E}-02$ & $2.1281 \mathrm{E}-05$ & $1.4877 \mathrm{E}-01$ \\
1 & $8.9317 \mathrm{E}-09$ & $7.8845 \mathrm{E}-01$ & $9.9435 \mathrm{E}-06$ & $5.0837 \mathrm{E}-02$ & $1.8846 \mathrm{E}-05$ & $1.4763 \mathrm{E}-01$ \\
\hline & & & & & &
\end{tabular}

Table 4 Statistical demonstrations of the TFM nonlinear system based on nervous stomach model for $F(\Omega)$

\begin{tabular}{lllllll}
\hline$\Omega$ & $F(\Omega)$ & & & & & \\
\cline { 2 - 7 } & MIN & MAX & MED & MEAN & S.I.R & STD \\
\hline 0 & $6.5270 \mathrm{E}-09$ & $1.5847 \mathrm{E}-01$ & $2.8895 \mathrm{E}-06$ & $4.9346 \mathrm{E}-02$ & $2.0331 \mathrm{E}-05$ & $3.8381 \mathrm{E}-02$ \\
0.05 & $6.3223 \mathrm{E}-09$ & $1.6200 \mathrm{E}-01$ & $7.8341 \mathrm{E}-06$ & $4.9710 \mathrm{E}-02$ & $1.5025 \mathrm{E}-05$ & $4.0016 \mathrm{E}-02$ \\
0.1 & $1.1198 \mathrm{E}-07$ & $1.6668 \mathrm{E}-01$ & $1.2133 \mathrm{E}-05$ & $5.0075 \mathrm{E}-02$ & $2.4419 \mathrm{E}-05$ & $4.1957 \mathrm{E}-02$ \\
0.15 & $1.1656 \mathrm{E}-08$ & $1.7230 \mathrm{E}-01$ & $1.6517 \mathrm{E}-05$ & $5.0414 \mathrm{E}-02$ & $3.1475 \mathrm{E}-05$ & $4.4161 \mathrm{E}-02$ \\
0.2 & $1.4627 \mathrm{E}-07$ & $1.7789 \mathrm{E}-01$ & $2.0041 \mathrm{E}-05$ & $5.0721 \mathrm{E}-02$ & $3.3427 \mathrm{E}-05$ & $4.6494 \mathrm{E}-02$ \\
0.25 & $3.6429 \mathrm{E}-07$ & $1.8277 \mathrm{E}-01$ & $1.8511 \mathrm{E}-05$ & $5.0994 \mathrm{E}-02$ & $3.1187 \mathrm{E}-05$ & $4.8867 \mathrm{E}-02$ \\
0.3 & $4.8942 \mathrm{E}-07$ & $1.8678 \mathrm{E}-01$ & $1.6426 \mathrm{E}-05$ & $5.1234 \mathrm{E}-02$ & $2.3122 \mathrm{E}-05$ & $5.1256 \mathrm{E}-02$ \\
0.35 & $1.2992 \mathrm{E}-08$ & $1.9005 \mathrm{E}-01$ & $1.2868 \mathrm{E}-05$ & $5.1440 \mathrm{E}-02$ & $1.8730 \mathrm{E}-05$ & $5.3677 \mathrm{E}-02$ \\
0.4 & $1.8807 \mathrm{E}-07$ & $1.9291 \mathrm{E}-01$ & $1.5984 \mathrm{E}-05$ & $5.1613 \mathrm{E}-02$ & $2.0729 \mathrm{E}-05$ & $5.6160 \mathrm{E}-02$ \\
0.45 & $8.0425 \mathrm{E}-08$ & $1.9566 \mathrm{E}-01$ & $1.0989 \mathrm{E}-05$ & $5.1753 \mathrm{E}-02$ & $2.8507 \mathrm{E}-05$ & $5.8731 \mathrm{E}-02$ \\
0.5 & $2.7672 \mathrm{E}-08$ & $1.9855 \mathrm{E}-01$ & $9.2933 \mathrm{E}-06$ & $5.1859 \mathrm{E}-02$ & $3.6436 \mathrm{E}-05$ & $6.1398 \mathrm{E}-02$ \\
0.55 & $6.7093 \mathrm{E}-08$ & $2.0178 \mathrm{E}-01$ & $1.3249 \mathrm{E}-05$ & $5.1930 \mathrm{E}-02$ & $3.9531 \mathrm{E}-05$ & $6.4161 \mathrm{E}-02$ \\
0.6 & $2.6265 \mathrm{E}-08$ & $2.0543 \mathrm{E}-01$ & $1.6354 \mathrm{E}-05$ & $5.1965 \mathrm{E}-02$ & $3.6066 \mathrm{E}-05$ & $6.7008 \mathrm{E}-02$ \\
0.65 & $3.1232 \mathrm{E}-07$ & $2.0956 \mathrm{E}-01$ & $1.6759 \mathrm{E}-05$ & $5.1962 \mathrm{E}-02$ & $3.2684 \mathrm{E}-05$ & $6.9921 \mathrm{E}-02$ \\
0.7 & $3.4493 \mathrm{E}-07$ & $2.1417 \mathrm{E}-01$ & $9.7510 \mathrm{E}-06$ & $5.1921 \mathrm{E}-02$ & $3.6482 \mathrm{E}-05$ & $7.2878 \mathrm{E}-02$ \\
0.75 & $6.5588 \mathrm{E}-08$ & $2.1921 \mathrm{E}-01$ & $1.4620 \mathrm{E}-05$ & $5.1839 \mathrm{E}-02$ & $3.5535 \mathrm{E}-05$ & $7.5855 \mathrm{E}-02$ \\
0.8 & $1.7331 \mathrm{E}-07$ & $2.2462 \mathrm{E}-01$ & $1.1167 \mathrm{E}-05$ & $5.1719 \mathrm{E}-02$ & $2.9052 \mathrm{E}-05$ & $7.8829 \mathrm{E}-02$ \\
0.85 & $6.4139 \mathrm{E}-08$ & $2.3033 \mathrm{E}-01$ & $1.1033 \mathrm{E}-05$ & $5.1559 \mathrm{E}-02$ & $2.7092 \mathrm{E}-05$ & $8.1777 \mathrm{E}-02$ \\
0.9 & $1.6285 \mathrm{E}-07$ & $2.3626 \mathrm{E}-01$ & $1.7870 \mathrm{E}-05$ & $5.1359 \mathrm{E}-02$ & $3.4195 \mathrm{E}-05$ & $8.4676 \mathrm{E}-02$ \\
0.95 & $1.7341 \mathrm{E}-08$ & $2.4231 \mathrm{E}-01$ & $1.7346 \mathrm{E}-05$ & $5.1119 \mathrm{E}-02$ & $3.2284 \mathrm{E}-05$ & $8.7510 \mathrm{E}-02$ \\
1 & $6.0135 \mathrm{E}-08$ & $2.4841 \mathrm{E}-01$ & $1.0206 \mathrm{E}-05$ & $5.0837 \mathrm{E}-02$ & $2.0501 \mathrm{E}-05$ & $9.0262 \mathrm{E}-02$ \\
\hline & & & & & &
\end{tabular}


Table 5 Statistical demonstrations of the TFM nonlinear system based on nervous stomach model for $M(\Omega)$

\begin{tabular}{lllllll}
\hline$\Omega$ & $M(\Omega)$ & & & & & \\
\cline { 2 - 7 } & MIN & MAX & MED & MEAN & S.I.R & STD \\
\hline 0 & $3.2202 \mathrm{E}-08$ & $4.3306 \mathrm{E}-01$ & $5.9783 \mathrm{E}-06$ & $4.9346 \mathrm{E}-02$ & $7.9928 \mathrm{E}-06$ & $7.4405 \mathrm{E}-02$ \\
0.05 & $1.7206 \mathrm{E}-07$ & $4.4980 \mathrm{E}-01$ & $1.1027 \mathrm{E}-05$ & $4.9710 \mathrm{E}-02$ & $2.8302 \mathrm{E}-05$ & $8.3762 \mathrm{E}-02$ \\
0.1 & $1.8845 \mathrm{E}-07$ & $4.6430 \mathrm{E}-01$ & $1.2855 \mathrm{E}-05$ & $5.0075 \mathrm{E}-02$ & $1.7310 \mathrm{E}-05$ & $8.6884 \mathrm{E}-02$ \\
0.15 & $8.8678 \mathrm{E}-07$ & $4.7719 \mathrm{E}-01$ & $1.2660 \mathrm{E}-05$ & $5.0414 \mathrm{E}-02$ & $2.2163 \mathrm{E}-05$ & $9.0174 \mathrm{E}-02$ \\
0.2 & $9.8560 \mathrm{E}-07$ & $4.8905 \mathrm{E}-01$ & $1.5342 \mathrm{E}-05$ & $5.0721 \mathrm{E}-02$ & $5.3827 \mathrm{E}-05$ & $9.3909 \mathrm{E}-02$ \\
0.25 & $2.8520 \mathrm{E}-07$ & $5.0039 \mathrm{E}-01$ & $1.7978 \mathrm{E}-05$ & $5.0994 \mathrm{E}-02$ & $7.9268 \mathrm{E}-05$ & $9.8042 \mathrm{E}-02$ \\
0.3 & $1.8755 \mathrm{E}-07$ & $5.1171 \mathrm{E}-01$ & $1.4899 \mathrm{E}-05$ & $5.1234 \mathrm{E}-02$ & $9.3873 \mathrm{E}-05$ & $1.0257 \mathrm{E}-01$ \\
0.35 & $1.0799 \mathrm{E}-07$ & $5.2341 \mathrm{E}-01$ & $1.3885 \mathrm{E}-05$ & $5.1440 \mathrm{E}-02$ & $9.6093 \mathrm{E}-05$ & $1.0748 \mathrm{E}-01$ \\
0.4 & $4.3101 \mathrm{E}-08$ & $5.3584 \mathrm{E}-01$ & $1.5077 \mathrm{E}-05$ & $5.1613 \mathrm{E}-02$ & $8.6513 \mathrm{E}-05$ & $1.1275 \mathrm{E}-01$ \\
0.45 & $2.2963 \mathrm{E}-08$ & $5.4930 \mathrm{E}-01$ & $1.3395 \mathrm{E}-05$ & $5.1753 \mathrm{E}-02$ & $6.9837 \mathrm{E}-05$ & $1.1837 \mathrm{E}-01$ \\
0.5 & $4.2660 \mathrm{E}-07$ & $5.6403 \mathrm{E}-01$ & $1.6463 \mathrm{E}-05$ & $5.1859 \mathrm{E}-02$ & $4.7446 \mathrm{E}-05$ & $1.2431 \mathrm{E}-01$ \\
0.55 & $6.9731 \mathrm{E}-08$ & $5.8022 \mathrm{E}-01$ & $1.9561 \mathrm{E}-05$ & $5.1930 \mathrm{E}-02$ & $3.6602 \mathrm{E}-05$ & $1.3053 \mathrm{E}-01$ \\
0.6 & $4.4237 \mathrm{E}-08$ & $5.9801 \mathrm{E}-01$ & $2.1426 \mathrm{E}-05$ & $5.1965 \mathrm{E}-02$ & $2.2380 \mathrm{E}-05$ & $1.3700 \mathrm{E}-01$ \\
0.65 & $4.8849 \mathrm{E}-07$ & $6.1747 \mathrm{E}-01$ & $2.0258 \mathrm{E}-05$ & $5.1962 \mathrm{E}-02$ & $2.1955 \mathrm{E}-05$ & $1.4366 \mathrm{E}-01$ \\
0.7 & $2.8924 \mathrm{E}-07$ & $6.3865 \mathrm{E}-01$ & $1.8394 \mathrm{E}-05$ & $5.1921 \mathrm{E}-02$ & $2.5179 \mathrm{E}-05$ & $1.5049 \mathrm{E}-01$ \\
0.75 & $9.4608 \mathrm{E}-08$ & $6.6157 \mathrm{E}-01$ & $1.7304 \mathrm{E}-05$ & $5.1839 \mathrm{E}-02$ & $2.9645 \mathrm{E}-05$ & $1.5745 \mathrm{E}-01$ \\
0.8 & $1.5647 \mathrm{E}-07$ & $6.8620 \mathrm{E}-01$ & $1.5056 \mathrm{E}-05$ & $5.1719 \mathrm{E}-02$ & $2.9400 \mathrm{E}-05$ & $1.6452 \mathrm{E}-01$ \\
0.85 & $3.6004 \mathrm{E}-07$ & $7.1248 \mathrm{E}-01$ & $1.3367 \mathrm{E}-05$ & $5.1559 \mathrm{E}-02$ & $4.4082 \mathrm{E}-05$ & $1.7173 \mathrm{E}-01$ \\
0.9 & $7.5509 \mathrm{E}-08$ & $7.4035 \mathrm{E}-01$ & $1.5593 \mathrm{E}-05$ & $5.1359 \mathrm{E}-02$ & $6.4174 \mathrm{E}-05$ & $1.7916 \mathrm{E}-01$ \\
0.95 & $6.0356 \mathrm{E}-08$ & $7.6972 \mathrm{E}-01$ & $1.6278 \mathrm{E}-05$ & $5.1119 \mathrm{E}-02$ & $7.3466 \mathrm{E}-05$ & $1.8697 \mathrm{E}-01$ \\
1 & $4.4031 \mathrm{E}-07$ & $8.0048 \mathrm{E}-01$ & $1.5492 \mathrm{E}-05$ & $5.0837 \mathrm{E}-02$ & $5.8865 \mathrm{E}-05$ & $1.9545 \mathrm{E}-01$ \\
\hline & & & & & &
\end{tabular}

Table 6 Global measures performances of the TFM nonlinear system based on nervous stomach model

\begin{tabular}{|c|c|c|c|c|c|c|}
\hline \multirow[t]{2}{*}{$\Omega$} & \multicolumn{2}{|l|}{ (G-TIC) } & \multicolumn{2}{|l|}{ (G-MAD) } & \multicolumn{2}{|l|}{ (G-EVAF) } \\
\hline & MED & S.I.R & MED & S.I.R & MED & S.I.R \\
\hline$T(\Omega)$ & $1.21122 \mathrm{E}-05$ & $2.34591 \mathrm{E}-06$ & $2.63184 \mathrm{E}-10$ & $5.54466 \mathrm{E}-09$ & $1.29855 \mathrm{E}-08$ & $1.19791 \mathrm{E}-07$ \\
\hline$F(\Omega)$ & $1.48820 \mathrm{E}-06$ & $2.33652 \mathrm{E}-06$ & $3.21255 \mathrm{E}-09$ & $5.48223 \mathrm{E}-10$ & $1.77410 \mathrm{E}-08$ & $1.18326 \mathrm{E}-07$ \\
\hline$M(\Omega)$ & $1.60440 \mathrm{E}-05$ & $3.96309 \mathrm{E}-07$ & $3.34946 \mathrm{E}-09$ & $8.85668 \mathrm{E}-09$ & $1.67726 \mathrm{E}-09$ & $3.80989 \mathrm{E}-08$ \\
\hline
\end{tabular}

Funding Taif University Researchers Supporting Project number (TURSP-2020/349), Taif university, Taif, Saudi Arabia.

\section{Declarations}

Conflict of interest The authors state that they are not in any conflict of interest.

Open Access This article is licensed under a Creative Commons Attribution 4.0 International License, which permits use, sharing, adaptation, distribution and reproduction in any medium or format, as long as you give appropriate credit to the original author(s) and the source, provide a link to the Creative Commons licence, and indicate if changes were made. The images or other third party material in this article are included in the article's Creative Commons licence, unless indicated otherwise in a credit line to the material. If material is not included in the article's Creative Commons licence and your intended use is not permitted by statutory regulation or exceeds the permitted use, you will need to obtain permission directly from the copyright holder. To view a copy of this licence, visit http://creativecommons.org/licenses/by/4.0/.

\section{References}

1. Modlin, I. M.: From prout to the proton pump. Schnetztor-Verlag GmbH Konstanz (1995)

2. Pagel, W.: Joan Baptista van Helmont: reformer of science and medicine. Cambridge University Press (2002)

3. Goodrick-Clarke, N. (ed.) Paracelsus (Vol. 1). North Atlantic Books (1999)

4. de Réaumur, R.F.: Observations sur la digestion des oiseaux. Histoire de l'academieroyale des sciences 266, 461 (1752)

5. Spallanzani, L. Dissertazioni di Fisicaanimale e vegetabile (Vol. 2). Presso La Societa'Tipografica (1780)

6. Prout, W.: III. On the nature of the acid and saline matters usually existing in the stomachs of animals. Philos. Trans. R. Soc. Lond. 114, 45-49 (1824)

7. Beaumont, W.: Further experiments on the case of Alexis San Martin, who was wounded in the stomach by a load of duck-shot: detailed in the recorder for Jan. 1825 (1825) 
8. Dale, H.H.: Comment on paper 23 in: adventures in physiology, a selection from the scientific publications of Sir Henry Hallett Dale (1953)

9. Popielski, L.: $\beta$-Imidazolylathyaminind die organextracteersterteil. Pflug. Arch. 178, 214-236 (1920)

10. Black, J.W., Duncan, W.A.M., Durant, C.J., Ganellin, C.R., Parsons, E.M.: Definition and antagonism of histamine H2-receptors. Nature 236(5347), 385-390 (1972)

11. Edkins, J.S.: The chemical mechanism of gastric secretion 1. J. Physiol. 34(1-2), 133-144 (1906)

12. Bayliss, W.M., Starling, E.: Preliminary communication on the causation of the so-called" peripheral reflex secretion" of the pancreas. Lancet 159(4099), 813 (1902)

13. Warren, J.R., Marshall, B.: Unidentified curved bacilli on gastric epithelium in active chronic gastritis. Lancet 321(8336), 12731275 (1983)

14. Jaworski, W.: Podrêcznikchoróbzoladka (Handbook of Gastric Diseases). WydawnictwaDzielLekarskich Polskich, p. 30 (1899)

15. Guerrero Sánchez, Y., Sabir, Z., Günerhan, H., Baskonus, H.M.: Analytical and approximate solutions of a novel nervous stomach mathematical model. Discrete Dyn. Nat. Soc. 2020, 5063271 (2020). https://www.hindawi.com/journals/ddns/2020/5063271/

16. Sabir, Z., et al.: Heuristic computing technique for numerical solutions of nonlinear fourth order Emden-Fowler equation. Math. Comput. Simul. 178, 534-548 (2020)

17. Sabir, Z., et al.: Integrated intelligent computing with neuroswarming solver for multi-singular fourth-order nonlinear EmdenFowler equation. Comput. Appl. Math. 39(4), 1-18 (2020)

18. Sabir, Z., et al.: Design of neuro-swarming-based heuristics to solve the third-order nonlinear multi-singular Emden-Fowler equation. Eur. Phys. J. Plus 135(6), 410 (2020)

19. Naz, S., et al.: Neuro-intelligent networks for Bouc-Wen hysteresis model for piezostage actuator. Eur. Phys. J. Plus 136(4), 1-20 (2021)

20. Ilyas, H., et al.: A novel design of Gaussian wavelet neural networks for nonlinear Falkner-Skan systems in fluid dynamics. Chin. J. Phys. 72, 386-402 (2021)

21. Sabir, Z., et al.: A novel design of fractional Meyer wavelet neural networks with application to the nonlinear singular fractional Lane-Emden systems. Alex. Eng. J. 60(2), 2641-2659 (2021)

22. Sabir, Z., Raja, M.A.Z., Baleanu, D.: Fractional Mayer Neuroswarm heuristic solver for multi-fractional Order doubly singular model based on Lane-Emden equation. Fractals 29(5), 21400171219 (2021). https://www.worldscientific.com/doi/pdf/10.1142/ S0218348X2140017X

23. Raja, M.A.Z., Khan, Z., Zuhra, S., Chaudhary, N.I., Khan, W.U., He, Y., Islam, S., Shoaib, M.: Cattaneo-christov heat flux model of 3D hall current involving biconvection nanofluidic flow with Darcy-Forchheimer law effect: backpropagation neural networks approach. Case Stud. Therm. Eng. 101168 (2021)

24. Uddin, I., et al.: Design of intelligent computing networks for numerical treatment of thin film flow of Maxwell nanofluid over a stretched and rotating surface. Surf. Interfaces 24, 101107 (2021)

25. Shoaib, M., Raja, M.A.Z., Khan, M.A.R., Farhat, I., Awan, S.E.: Neuro-computing networks for entropy generation under the influence of MHD and thermal radiation. Surf. Interfaces 25, 101243 (2021). https://www.sciencedirect.com/science/article/abs/pii/ S2468023021003205

26. Umar, M., et al.: Intelligent computing for numerical treatment of nonlinear prey-predator models. Appl. Soft Comput. 80, 506-524 (2019)

27. Mehmood, A., et al.: Design of nature-inspired heuristic paradigm for systems in nonlinear electrical circuits. Neural Comput. Appl. 32(11), 7121-7137 (2020)

28. Umar, M., et al.: A stochastic computational intelligent solver for numerical treatment of mosquito dispersal model in a heterogeneous environment. Eur. Phys. J. Plus 135(7), 1-23 (2020)

29. Ahamd, S.I., et al.: A new heuristic computational solver for nonlinear singular Thomas-Fermi system using evolutionary optimized cubic splines. Eur. Phys. J. Plus 135(1), 1-29 (2020)

30. Raja, M.A.Z., et al.: Numerical solution of doubly singular nonlinear systems using neural networks-based integrated intelligent computing. Neural Comput. Appl. 31(3), 793-812 (2019)

31. Sabir, Z., et al.: FMNEICS: fractional Meyer neuro-evolutionbased intelligent computing solver for doubly singular multi-fractional order Lane-Emden system. Comput. Appl. Math. 39(4), $1-18(2020)$

32. Zameer, A., et al.: Fractional-order particle swarm based multiobjective PWR core loading pattern optimization. Ann. Nucl. Energy 135, 106982 (2020)

33. Muhammad, Y., Khan, R., Ullah, F., Aslam, M.S., Raja, M.A.Z.: Design of fractional swarming strategy for solution of optimal reactive power dispatch. Neural Comput. Appl. 32(14), 1050110518 (2020)

34. Umar, M., et al.: A stochastic numerical computing heuristic of SIR nonlinear model based on dengue fever. Results Phys. 19, 103585 (2020)

35. Sabir, Z., et al.: Novel design of Morlet wavelet neural network for solving second order Lane-Emden equation. Math. Comput. Simul. 172, 1-14 (2020)

36. Tao, Z., Huiling, L., Wenwen, W., Xia, Y.: GA-SVM based feature selection and parameter optimization in hospitalization expense modeling. Appl. Soft Comput. 75, 323-332 (2019)

37. Hemanth, D.J., Anitha, J.: Modified genetic algorithm approaches for classification of abnormal magnetic resonance brain tumour images. Appl. Soft Comput. 75, 21-28 (2019)

38. Zameer, A., et al.: Bio-inspired heuristics for layer thickness optimization in multilayer piezoelectric transducer for broadband structures. Soft. Comput. 23(10), 3449-3463 (2019)

39. Raja, M.A.Z., Ahmed, U., Zameer, A., Kiani, A.K., Chaudhary, N.I.: Bio-inspired heuristics hybrid with sequential quadratic programming and interior-point methods for reliable treatment of economic load dispatch problem. Neural Comput. Appl. 31(1), $447-475$ (2019)

40. Ilyas, H., et al.: A novel design of Gaussian wavelet neural networks for nonlinear Falkner-Skan systems in fluid dynamics. Chin. J. Phys. (2021)

41. Sabir, Z., Raja, M.A.Z., Wahab, H.A., Shoaib, M., Aguilar, J.G.: Integrated neuro-evolution heuristic with sequential quadratic programming for second-order prediction differential models. Numer. Methods Partial Differ. Equ. (Pre-online, Early View) (2020). https://onlinelibrary.wiley.com/doi/abs/10.1002/num.22692

42. Yang, Y., Yang, B., Wang, S., Liu, F., Wang, Y., Shu, X.: A dynamic ant-colony genetic algorithm for cloud service composition optimization. Int. J. Adv. Manuf. Technol. 102(1-4), 355-368 (2019)

43. Sabir, Z., et al.: A neuro-swarming intelligence-based computing for second order singular periodic non-linear boundary value problems. Front. Phys 8, 224 (2020)

44. Jiang, Y., Wu, P., Zeng, J., Zhang, Y., Zhang, Y., Wang, S.: Multiparameter and multi-objective optimisation of articulated monorail vehicle system dynamics using genetic algorithm. Veh. Syst. Dyn. 58(1), 74-91 (2020)

45. Mehmood, A., et al.: Integrated computational intelligent paradigm for nonlinear electric circuit models using neural networks, genetic algorithms and sequential quadratic programming. Neural Comput. Appl. 32(14), 10337-10357 (2020)

46. Montoya, O.D., Gil-González, W., Garces, A.: Sequential quadratic programming models for solving the OPF problem in DC grids. Electr. Power Syst. Res. 169, 18-23 (2019) 
47. Gharaei, A., Pasandideh, S.H.R.: Modeling and optimization of four-level integrated supply chain with the aim of determining the optimum stockpile and period length: sequential quadratic programming. J. Ind. Prod. Eng. 34(7), 529-541 (2017)

48. Long, K., Wang, X., Liu, H.: Stress-constrained topology optimization of continuum structures subjected to harmonic force excitation using sequential quadratic programming. Struct. Multidiscip. Optim. 59(5), 1747-1759 (2019)

49. Witkowska, A., Śmierzchalski, R.: Adaptive dynamic control allocation for dynamic positioning of marine vessel based on backstepping method and sequential quadratic programming. Ocean Eng. 163, 570-582 (2018)

50. Long, K., Wang, X., Gu, X.: Multi-material topology optimization for the transient heat conduction problem using a sequential quadratic programming algorithm. Eng. Optim. 50(12), 2091-2107 (2018)

51. Awan, S.E., et al.: Numerical computing paradigm for investigation of micropolar nanofluid flow between parallel plates system with impact of electrical MHD and Hall current. Arab. J. Sci. Eng. 46(1), 645-662 (2021)

52. Awan, S.E., et al.: Numerical treatments to analyze the nonlinear radiative heat transfer in MHD nanofluid flow with solar energy. Arab. J. Sci. Eng. 45, 4975-4994 (2020)

53. Shoaib, M., et al.: A stochastic numerical analysis based on hybrid NAR-RBFs networks nonlinear SITR model for novel COVID-19 dynamics. Comput. Methods Prog. Biomed. 202, 105973 (2021)

54. Ahmad, I., et al.: Novel applications of intelligent computing paradigms for the analysis of nonlinear reactive transport model of the fluid in soft tissues and microvessels. Neural Comput. Appl. 31(12), 9041-9059 (2019)

55. Ahmad, I., et al.: Integrated neuro-evolution-based computing solver for dynamics of nonlinear corneal shape model numerically. Neural Comput. Appl. 33(11), 5753-5769 (2021)

56. Bukhari, A.H., et al.: Fractional neuro-sequential ARFIMA-LSTM for financial market forecasting. IEEE Access 8, 71326-71338 (2020)

57. Ara, A., et al.: Wavelets optimization method for evaluation of fractional partial differential equations: an application to financial modelling. Adv. Difference Equ. 2018(1), 1-13 (2018)

58. Umar, M., et al.: The 3-D flow of Casson nanofluid over a stretched sheet with chemical reactions, velocity slip, thermal radiation and Brownian motion. Therm. Sci. 24(5 Part A), 2929-2939 (2020)

59. Umar, M., et al.: Numerical treatment for the three-dimensional Eyring-Powell fluid flow over a stretching sheet with velocity slip and activation energy. Adv. Math. Phys. 2019, 9860471 (2019). https://www.hindawi.com/journals/amp/2019/9860471/

60. Sabir, Z., et al.: Integrated intelligence of neuro-evolution with sequential quadratic programming for second-order Lane-Emden pantograph models. Math. Comput. Simul. 188, 87-101 (2021)

Publisher's Note Springer Nature remains neutral with regard to jurisdictional claims in published maps and institutional affiliations. 